\title{
PENGUJIAN NEUROTICISM SEBAGAI MODERATOR PADA HUBUNGAN ANTARA SENSITIVITAS ATASAN DENGAN PERILAKU KERJA KONTRAPRODUKTIF BAWAHAN (STUDI KASUS DI PT XYZ)
}

\author{
Tri Hartati ${ }^{1}$, Rostiana ${ }^{2}$, dan P. Tommy Y.S Suyasa ${ }^{3}$ \\ ${ }^{1}$ Program Studi Magister Psikologi, Universitas Tarumanagara, Jakarta \\ Email: hartati_tri@yahoo.com \\ ${ }^{2}$ Program Studi Magister Psikologi, Universitas Tarumanagara, Jakarta \\ Email: rostiana@fpsi.untar.ac.id \\ ${ }^{3}$ Program Studi S1 Psikologi, Universitas Tarumanagara, Jakarta \\ Email: tommys@fpsi.untar.ac.id
}

\begin{abstract}
This study aims to determine the role of neuroticism as a moderator in the relationship between the sensitivity of the superiors and counterproductive-organizational work behavior. Employees exhibiting highly counterproductive work behavior, where the indicators include arriving late, using work time for personal gain, extending breaks over specified time period. Counterproductive work behavior is a voluntary behavior that violates organizational norms / rules or the rules of its members, or both. The sensitivity of the superiors includes understanding behavior, sincere feelings, and readiness to help shown by superiors to subordinates. Neuroticism is an anxiety, insecurity, self-awareness, and temperamental, with basic behaviors such as anxious, restless, and irrational fear. The sample in this study are 123 participants. Sampling techniques used is simple random sampling. The method used for data analysis is descriptive statistics to describe each variable, Pearson parametric to test the correlation matrix, and Moderated Regression Analysis (MRA) to test the role of neuroticism as a moderator. The result of this study is that neuroticism has not been proven to be able to act as a moderator in the relationship between the sensitivity of superiors and counterproductive work behavior.
\end{abstract} Keywords: counterproductive work behavior, sensitivity of the superiors, neuroticism

\begin{abstract}
ABSTRAK
Penelitian ini bertujuan untuk mengetahui peran neuroticism sebagai moderator pada hubungan antara sensitivitas atasan dengan perilaku kerja kontraproduktif-organisasi. Karyawan menunjukkan perilaku kerja kontraproduktif yang tinggi, indikatornya adalah datang terlambat, menggunakan waktu kerja untuk kepentingan pribadi, memperpanjang waktu istirahat melebihi yang ditentukan. Perilaku kerja kontraproduktif merupakan perilaku sukarela yang melanggar norma/aturan organisasi atau aturan anggota-anggotanya, atau keduanya. Sensitivitas atasan yaitu perilaku memahami, perasaan tulus, dan kesiapan menolong yang ditunjukan oleh atasan kepada bawahannya. Neuroticism yaitu suatu kecemasan, tidak aman, kesadaran diri, dan temperamental, dengan dasar perilaku seperti cemas, gelisah, dan ketakutan yang tidak rasional. Sampel dalam penelitian ini sebanyak 123 partisipan. Tehnik pengambilan sampel dengan menggunakan simple random sampling. Metode yang digunakan untuk analis data yaitu descriptive statistic untuk mengetahui gambaran masing-masing variabel, parametrik pearson untuk menguji matriks korelasi, serta Moderated Regression Analysis (MRA) untuk menguji peran neuroticism sebagai moderator. Hasil pada penelitian ini adalah
\end{abstract}


PENGUJIAN NEUROTICISM SEBAGAI

MODERATOR PADA HUBUNGAN ANTARA

SENSITIVITAS ATASAN DENGAN PERILAKU

KERJA KONTRAPRODUKTIF BAWAHAN

(STUDI KASUS DI PT XYZ)

neuroticism belum terbukti dapat berperan sebagai moderator dalam hubungan antara sensitivitas atasan dengan perilaku kerja kontraproduktif.

Kata kunci: Perilaku kerja kontraproduktif, sensitivitas atasan, neuroticism
Tri Hartati, Rostiana dan P. Tommy Y.S Suyasa

\section{PENDAHULUAN}

PT XYZ adalah salah satu perusahaan asuransi yang sedang berkembang pesat. Selama lebih dari 25 tahun berdiri, PT XYZ telah memiliki lebih dari 10 kantor cabang dan pemasaran yang tersebar di beberapa propinsi di Indonesia. Selama kurun waktu tersebut, PT XYZ telah berhasil meningkatkan jumlah aset yang dimiliki setiap tahunnya melalui peningkatan penjualan dan meminimalisir risiko klaim. PT XYZ pun telah beberapa kali mendapat penghargaan dari majalah asuransi atas kinerja keuangan yang terbaik.

Untuk mempertahankan prestasi perusahaan, karyawan PT XYZ perlu menunjukkan perilaku kerja yang positif. Adapun perilaku kerja dimaksud meliputi semangat dalam bekerja, rajin, tekun, bekerja dengan cepat, tidak memilih pekerjaan, bekerja sama, bekerja dengan jujur, benar dan sungguh-sungguh, serta mengikuti aturan dan prosedur yang ditetapkan perusahaan. Namun demikian, beberapa karyawan menunjukkan perilaku kerja yang negatif, seperti datang terlambat, hadir di tempat kerja namun tidak langsung bekerja, menggunakan waktu istirahat secara berlebihan, serta menggunakan waktu kerja untuk berdagang, makan pagi, atau mendiskusikan hal lain yang bukan berkaitan dengan pekerjaan. Perilaku kerja negatif sebagaimana yang disebutkan di atas, dapat mengakibatkan pekerjaan tidak selesai tepat waktu serta membutuhkan waktu kerja tambahan. Waktu kerja tambahan dikompensasikan oleh karyawan sebagai kerja lembur. Akibatnya berpotensi meningkatnya biaya lembur perusahaan dan mengurangi laba perusahaan. Keterlambatan kerja juga dikeluhkan oleh salah seorang manager karena menyebabkan penerbitan polis menjadi terlambat.

Perilaku kerja negatif lainnya yang bertentangan dengan peraturan dan standard operating procedure (SOP) perusahaan adalah penggunaan rekening pribadi untuk penerimaan pembayaran premi nasabah, pembayaran klaim ke nasabah tanpa melalui proses survei, maupun adanya agen fiktif. Perilaku kerja ini berpotensi perusahaan mengalami kerugian, di antaranya data calon nasabah yang tidak akurat/tidak sesuai sehingga risiko klaim tidak dapat dicegah/diantisipasi. Akibat kesalahan tersebut, karyawan dimaksud akan mendapat surat peringatan atau surat teguran. Perilaku kerja negatif yang dilakukan oleh karyawan dalam bidang psikologi dikenal dengan istilah counterproductive work behavior (perilaku kerja kontraproduktif). Perilaku kontraproduktif merupakan perilaku yang disengaja dan bertentangan dengan kepentingan sah organisasi (Robinson \& Greenberg, dalam Sackett \& DeVore, 2005). Perilaku kerja kontraproduktif berbahaya bagi organisasi, dan hal ini telah dijelaskan oleh Dunlop dan Lee (2004), dimana perilaku kerja kontraproduktif 
memengaruhi fungsi unit bisnis secara keseluruhan serta berdampak terhadap efektifitas organisasi, sehingga diperkirakan organisasi kehilangan modal/dana yang tidak sedikit.

Menurut penelitian yang dilakukan oleh Rupprecht, Kueny, Shoss, dan Metzger (2016), perilaku kerja kontraproduktif diprediksi oleh leader sensitivity (sensitivitas atasan). Sensititivitas atasan yaitu perilaku memahami, perasaan tulus, dan kesiapan menolong (Epitropaki \& Martin, 2005), serta sikap percaya, menghormati, dan hangat (Rupprecht et al., 2016) yang ditampilkan oleh atasan. Dari hasil penelitiannya, Rupprecht et al. (2016) menemukan bahwa kesesuaian sensitivitas atasan yang diharapkan dengan kenyataan yang diterima, akan memprediksi afek negatif dan perilaku kerja kontraproduktif karyawan. Pada saat sensitivitas atasan sesuai dengan yang diharapkan, karyawan akan mengalami penurunan afek negatif sehingga menurunkan perilaku kerja kontraproduktif. Rupprecht et al. (2016) juga menemukan bahwa karyawan yang mengalami sensitivitas yang tinggi dari atasan, menunjukkan perilaku kerja kontraproduktif yang rendah dibandingkan karyawan yang mengalami sensitivitas yang rendah.

Pada penelitian Rupprecht et al. (2016), konsep perilaku kerja kontraproduktif yang digunakan dikembangkan oleh Spector, Fox, Penney, Bruursema, Goh, dan Kessler (2006). Konsep tersebut berdasarkan lima dimensi yaitu abuse again others, production deviance, sabotage, theft, dan withdrawal. Pada kenyataan yang terjadi di lapangan, perilaku kerja kontraproduktif yang muncul di PT XYZ tidak terlalu pas jika dikaji dengan konsep perilaku kerja kontraproduktif dari Spector et al. (2006). Perilaku yang muncul di PT XYZ banyak yang termasuk dalam dimensi kontraproduktif-O, yaitu perilaku yang membahayakan secara organisasi. Menurut Fida, Paciello, Tramontano, Fontaine, Barbaranelli, dan Farnese (2016), perilaku kerja kontraproduktif-O tidak berhubungan dengan konflik interpersonal, oleh sebab itu beberapa peneliti (Chullen, Dunford, Angermeier, Boss, \& Boss, 2010; Sulea, Fine, Fischmann, Sava, \& Dumitru, 2013) telah mengkhususkan penelitian hanya pada dimensi perilaku kerja kontraproduktif-I atau kontraproduktif-O. Dengan pertimbangan tersebut, fenomena yang ada di PT XYZ akan dijelaskan dengan menggunakan konsep yang dikembangkan oleh Bennett dan Robinson (2000) khususnya pada konsep perilaku kerja kontraproduktif yang bersifat organisasi (CWBO). Hal ini sependapat dengan yang dinyatakan Robinson dan Bennett (1995) bahwa setiap perilaku kerja kontraproduktif harus diuji sebagai fenomena organisasi yang penting dan berbeda sesuai dengan kondisinya.

Berdasarkan uraian di atas, pada penelitian Rupprecht et al. (2016) belum terjelaskan bagaimana sensitivitas atasan dapat memprediksi perilaku pada dimensi perilaku kerja kontraproduktif-organisasi secara khusus (CWB-O). 
PENGUJIAN NEUROTICISM SEBAGAI

MODERATOR PADA HUBUNGAN ANTARA

SENSITIVITAS ATASAN DENGAN PERILAKU

KERJA KONTRAPRODUKTIF BAWAHAN

(STUDI KASUS DI PT XYZ)

Selain itu, Rupprecht et al. (2016) belum menjelaskan perilaku kerja kontraproduktif berdasarkan pertimbangan faktor kepribadian. Perilaku kerja kontraproduktif diprediksi oleh faktor kepribadian (Mount, Ilies, \& Johnson, 2006). Faktor kepribadian merupakan faktor bawaan dan setiap individu berbeda-beda. Pada beberapa penelitian, salah satu faktor kepribadian yang berhubungan dengan perilaku kerja kontraproduktif adalah neuroticism (ChenLim, Yin-Fah, Benjamin, \& Jin Teh, 2016; Kozako, Safin, \& Rahim, 2013). Neuroticism merupakan suatu genetika atau warisan yang merupakan manifestasi biologi yang menunjukkan karakteristik perilaku yang berbeda antara individu dengan individu yang lainnya (Eysenck, dalam Schultz \& Schultz, 2005). Perbedaan tingkat neuroticism juga memengaruhi perilaku kerja kontraproduktif masing-masing individu, sehingga individu yang memiliki neuroticism tinggi akan meningkatkan perilaku kerja kontraproduktif, dan begitu pula sebaliknya (ChenLim et al., 2016; Kozako et al., 2013).

Berdasarkan uraian di atas, peneliti tertarik untuk mengetahui lebih jauh peran neuroticism yang dimiliki karyawan dalam memengaruhi hubungan antara sensitivitas dengan perilaku kerja kontraproduktif-organisasi. Penelitian Golparvar, Dehghan, dan Mehdad (2014), neuroticism dapat berperan sebagai moderator pada hubungan antara emotional exhaustion (kelelahan emosional) dengan perilaku kerja kontraproduktif. Oleh sebab itu peneliti menduga neuroticism juga dapat berperan sebagai moderator pada hubungan antara sensitivitas atasan dengan perilaku kerja kontraproduktif, yaitu pada saat neuroticism tinggi maka kelelahan emosional berhubungan secara positif dan signifikan dengan perilaku kerja kontraproduktif. Oleh sebab itu peneliti menduga neuroticism juga dapat berperan sebagai moderator pada hubungan antara sensitivitas atasan dengan perilaku kerja kontraproduktif. Berdasarkan uraian di atas dan didukung dari hasil penelitian sebelumnya maka peneliti tertarik untuk menguji peran neuroticism sebagai moderator pada hubungan antara sensitivitas atasan dengan perilaku kerja kontraproduktif-organisasi.

\section{Perilaku Kerja Kontraproduktif}

Perilaku kerja kontraproduktif merupakan perilaku sukarela yang melanggar norma/aturan organisasi atau aturan anggota-anggotanya, atau keduanya (Robinson \& Bennett, 1995); yang disengaja untuk merusak kepentingan legitimasi (legal) organisasi (Gruys \& Sackett, dalam Demerouti, Bakker, Halbesleben, 2015). Perilaku kerja kontraproduktif menjadi dua dimensi, yaitu perilaku kerja kontraproduktif-I dan perilaku kerja kontraproduktif-O (Bennett \& Robinson, 2000).

Penyebab munculnya perilaku kerja kontraproduktif, yaitu manusia, situasi, dan interaksionis (Sackett \& DeVore, 2005). Pada perspektif manusia, terfokus pada variabel individu yang berbeda-beda seperti ciri kepribadian. Pada perspektif situasional, terfokus pada ciri-ciri seperti norma kelompok, budaya organisasi, 
kebijakan dan praktik organisasi, serta sistem kontrol. Pada perspektif interaksionis, terfokus pada hubungan timbal-balik antara faktor manusia dengan situasi yang ada.

\section{Sensitivitas Atasan}

Istilah sensitivitas pertama kali dikembangkan oleh Offermann, Kennedy Jr., dan Wirtz (1994) yang meneliti tentang karakteristik atasan berdasarkan konsep teori implicit leadership theories (ILT). ILT merupakan teori kepemimpinan yang mendapat perhatian sebagai alat untuk memahami pemimpin melalui atribusi dan persepsi secara kognitif (Lord, Foti, \& DeVader, dalam Offerman et al., 1994). ILT juga menunjukkan bagaimana seorang karyawan (bawahan) memiliki keinginan (implisit) terhadap kualitas atau perilaku yang mereka yakini sebagai seorang pemimpin yang efektif (Epitropaki \& Martin, 2005).

Selanjutnya sensitivitas dikembangkan oleh Epitropaki dan Martin (2005) dengan menggunakan konsep ILT untuk memperkuat kualitas leader-member exchange (LMX). LMX merupakan persepsi terhadap atasan diantara sejumlah karyawan, yang didefinisikan sebagai persepsi karyawan secara menyeluruh terhadap kualitas hubungan dengan atasannya (Graen \& Scandura, dalam Chullen, et al., 2010), meliputi dukungan atasan secara emosional, kepercayaan atasan, dan feedback atasan (Dienesch \& Liden, dalam Chullen, et al., 2010). Faktor yang mempengaruhi sensitivitas atasan, diantaranya adalah jenis kelamin, dimana perempuan umumnya lebih berperasaan dibandingkan laki-laki (Deaux \& Kite; Portello \& Long, dalam Rupprecht et al., 2016).

\section{Neuroticism}

Neuroticism merupakan salah satu dari dimensi kepribadian The Big Five dan merupakan sisi negatif dari kepercayaan diri (Costa \& McCrae, 1988; dalam Judge, Locke, Durham, \& Kluger, 1998). Neuroticism didefinisikan sebagai suatu kecemasan, tidak aman, kesadaran diri, dan temperamental (McCrae \& Costa, 1987). Individu dengan kepribadian neuroticism rentan terhadap kecemasan, sebagai manifestasi dirinya cenderung takut terhadap situasi yang baru dan rentan terhadap perasaan ketergantungan dan tidak berdaya (Costa \& McCrae, 1988; dalam Judge, Locke, Durham, \& Kluger, 1998). Orang-orang yang memiliki neuroticism yang tinggi dilaporkan memiliki perasaan cemas, bersalah, tegang, dan moody, serta cenderung memiliki self-esteem yang rendah (Hans Eysenck, dalam Teferi, 2004).

Eysenck mengatakan bahwa neuroticism sebagian besar merupakan warisan keturunan (genetik), yang merupakan manifestasi biologis yang berbeda pada setiap manusia. Para peneliti genetika membuktikan adanya pengaruh genetik pada kepribadian. Pada sebuah studi perbandingan telah ditemukan bahwa neuroticism, 
PENGUJIAN NEUROTICISM SEBAGAI

MODERATOR PADA HUBUNGAN ANTARA

SENSITIVITAS ATASAN DENGAN PERILAKU

KERJA KONTRAPRODUKTIF BAWAHAN

(STUDI KASUS DI PT XYZ)

extraversion, openness, dan conscientiousness merupakan komponen genetika yang paling kuat terhadap kepribadian seseorang (Cattel, Eysenck, et al., 2005). Sedangkan agreeableness ditemukan memiliki komponen lingkungan yang paling kuat terhadap kepribadian seseorang (Bergeman et al., 1993; Pedersen et al., 1988, dalam Cattel, Eysenck, et al., 2005).

\section{Kerangka Berpikir dan Hipotesis}

Sensitivitas atasan merupakan salah satu karakteristik positif seorang pemimpin, meliputi perilaku memahami, tulus, dan menolong (Epitropaki \& Martin, 2005). Perilaku atasan merupakan model bagi bawahan, sehingga akan mempengaruhi psikologis bawahan. Hal ini ditunjang oleh beberapa penelitian yang menunjukan adanya keterkaitan yang kuat antara persepsi bawahan terhadap perilaku atasan dengan afeksi, kesejahteraan, dan perilaku bawahan (Conchie; Offermann \& Hellmann; van Dierendonck, Haynes, Borrill, \& Stride; dalam Rupprecht et al., 2016).

Atasan yang berperilaku kasar akan meningkatkan perilaku kerja kontraproduktif (Sulea et al., 2013), sedangkan atasan yang memiliki sikap positif akan mendorong perilaku normatif dan mengurangi probabilitas karyawan terikat dengan perilaku tidak etis (Mayer et al., dalam Ozbag, 2016), diantaranya perilaku kerja kontraproduktif. Salah satu sikap positif atasan, yaitu sensitivitas atasan, berkaitan dengan perilaku kerja kontraproduktif (Rupprecht et al., 2016). Dalam penelitiannya, Rupprecht et al. (2016) menemukan bahwa karyawan yang mengharap dan menerima sensitivitas atasan yang tinggi, akan mengalami penurunan afek yang pada akhirnya menurunkan perilaku kerja kontraproduktif. Sehingga karyawan yang menerima sensitivitas atasan yang tinggi memiliki keterlibatan yang rendah dalam perilaku kerja kontraproduktif, dibanding karyawan yang menerima sensitivitas atasan yang rendah.

Selain faktor situasional, perilaku kerja kontraproduktif juga diprediksi oleh faktor kepribadian (Sackett \& DeVore, 2005). Salah satu faktor kepribadian yang memprediksi perilaku kerja kontraproduktif adalah neuroticism (ChenLim, Yin-Fah, Benjamin, \& Jin Teh, 2016; Kozako, Safin, \& Rahim, 2013). Adanya perbedaan tingkat neuroticism juga mempengaruhi perilaku kerja kontraproduktif masing-masing individu, sehingga individu yang memiliki neuroticism tinggi akan meningkatkan perilaku kerja kontraproduktif, dan begitu pula sebaliknya (ChenLim et al., 2016; Kozako et al., 2013). Oleh sebab itu peneliti tertarik untuk mengetahui lebih jauh perbedaan tingkat neuroticism yang dimiliki karyawan dalam mempengaruhi hubungan antara sensitivitas dengan perilaku kerja kontraproduktif-organisasi. Peran neuroticism sebagai moderator pernah dilakukan oleh Golparvar, Dehghan, dan Mehdad (2014) dan menemukan bahwa neuroticism dapat berperan sebagai moderator pada hubungan antara emotional exhaustion (kelelahan emosional) dengan perilaku kerja kontraproduktif. Berdasarkan uraian di atas dan didukung dari hasil penelitian sebelumnya maka 
peneliti tertarik untuk menguji neuroticism sebagai moderator pada hubungan antara sensitivitas atasan dengan perilaku kerja kontraproduktif-organisasi.

Pada hubungan antara sensitifitas atasan dengan perilaku kerja kontraproduktif-organisasi, diprediksi bahwa semakin tinggi sensitifitas atasan maka semakin rendah perilaku kerja kontraproduktif-organisasi. Namun pada hubungan tersebut perlu dipertimbangkan pula adanya faktor neuroticism yang mempengaruhi hubungan tersebut. Berdasarkan hal tersebut, maka dapat disimpulkan bahwa neuroticism berpotensi mampu memperlemah hubungan antara sensitivitas atasan dengan perilaku kerja kontraproduktif-organisasi. Semakin tinggi skor neuroticism maka semakin lemah hubungan antara sensitivitas atasan dengan perilaku kontraproduktif-organisasi, dan sebaliknya semakin rendah skor neuroticism maka semakin kuat hubungan antara sensitivitas atasan dengan perilaku kerja kontraproduktif-organisasi.

Berdasarkan penjelasan di atas, hipotesis yang peneliti ajukan adalah:

$\mathrm{H}_{1}$ : Neuroticism dapat berperan sebagai moderator pada hubungan antara sensitivitas atasan dengan perilaku kerja kontraproduktif-organisasi

Dari uraian di atas, hubungan ketiga variabel dapat digambarkan sebagai berikut:

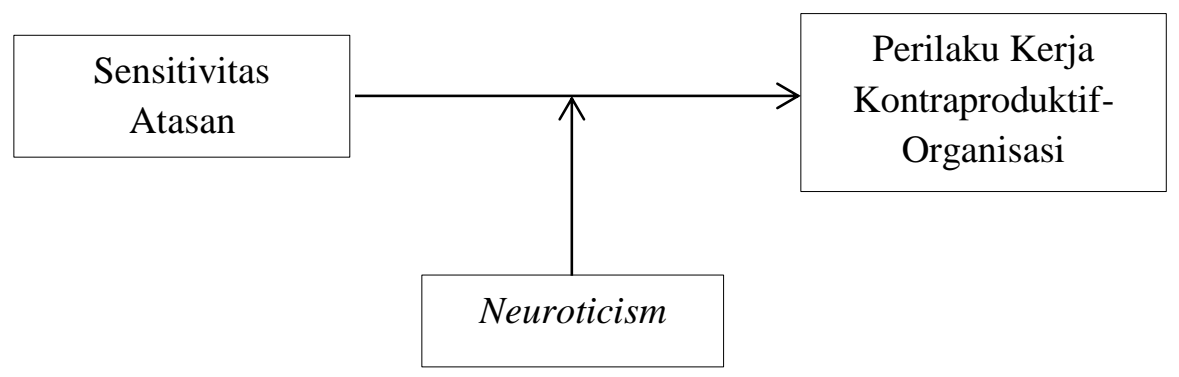

\section{METODE PENELITIAN}

Partisipan diambil dari karyawan PT XYZ. Jumlah partisipan sebanyak 123 orang. Berdasarkan demografinya, partisipan paling banyak berusia 35-38 tahun (18,7\%), berjenis kelamin laki-laki 77 orang $(62,6 \%)$, berpendidikan S1 sebanyak 91 orang (74\%), jabatan sebagai staff sebanyak 57 orang (46,3\%), berstatus tetap 104 orang $(84.6 \%)$, dan memiliki masa kerja di bawah 3,5 tahun $(26,8 \%)$.

Perilaku kerja kontraproduktif diukur dengan menggunakan Workplace Deviance yang dikembangkan oleh Bennett dan Robinson (2000). Butir yang digunakan sebanyak 23 butir pernyataan positif. Contoh butir "Meninggalkan tempat kerja (beristirahat) di luar waktu yang ditentukan". Hasil uji reliabilitas memiliki Cronbach Alpha 0.824. 
PENGUJIAN NEUROTICISM SEBAGAI

MODERATOR PADA HUBUNGAN ANTARA

SENSITIVITAS ATASAN DENGAN PERILAKU

KERJA KONTRAPRODUKTIF BAWAHAN

(STUDI KASUS DI PT XYZ)

Sensitivitas atasan diukur dengan menggunakan Leader Attributes Scale yang dikembangkan oleh Epitropaki dan Martin (2005). Butir yang digunakan sebanyak 8 butir pernyataan positif. Contoh butir "Atasan saya mengerti perasaan yang sedang dialami bawahan". Hasil uji reliabilitas memiliki Cronbach Alpha 0.864.

Neuroticism diukur dengan menggunakan NEO Personality Inventory yang dikembangkan oleh Costa dan McCrae (1992). Butir yang digunakan sebanyak 28 butir pernyataan positif dan 17 butir pernyataan negatif. Contoh butir positif "Saya seringkali ingin marah terhadap orang-orang yang kurang menghargai saya". Contoh butir negatif "Saya bukanlah seorang pencemas". Hasil uji reliabilitas memiliki Cronbach Alpha 0.897.

\section{HASIL PENELITIAN}

Skor mean, standar deviasi, reliabilitas, dan interkorelasi butir dengan total butir pada variabel perilaku kerja kontraproduktif, sensitivitas atasan, dan neuroticism diukur. Hasilnya sebagaimana tercantum pada Tabel 1.

Tabel 1

Deskripsi statistik dan Korelasi pada Semua Variabel

\begin{tabular}{lccccc}
\hline Variabel & & & \multicolumn{3}{c}{ Korelasi (r) } \\
\cline { 4 - 5 } & $\mathbf{M}$ & SD & $\mathbf{1}$ & $\mathbf{2}$ & $\mathbf{3}$ \\
\hline 1. Perilaku Kerja & 0,53 & 0,426 & $(0,824)$ & & \\
Kontraproduktif- & & & & & \\
Organisasi & & & & \\
2. Sensitivitas Atasan & 2,35 & 0,649 & $-0,089$ & $(0,864)$ & $(0,897)$ \\
3. Neuroticism & 3,05 & 0,54 & $0,367 * *$ & $-0,067$ & \\
& & & &
\end{tabular}

$\mathrm{N}=123 . * *$. Correlation is significant at the 0.01 level (2-tailed).

Sebagaimana yang tercantum pada Tabel 1, pada uji korelasi tidak ada hubungan antara sensitivitas atasan dengan perilaku kerja kontraproduktif $(\mathrm{r}=-0,089, p>0,01, p=0,329)$. Neuroticism memiliki hubungan dengan perilaku kerja kontraproduktif $(\mathrm{r}=0,367, p<0,01, p=0,000)$.

Uji asumsi meliputi uji normalitas, linieritas, multikolinieritas, autokorelasi, dan heteroskedastisitas dilakukan sebelum uji moderator. Selanjutnya untuk mengukur peran neuroticism sebagai moderator digunakan Moderated Regression Analysis (MRA). Tehnik yang dilakukan dengan menggabungkan variabel sensitivitas atasan dengan neuroticism untuk melihat interaksi keduanya serta pengaruhnya terhadap perilaku kerja kontraproduktif. Hasilnya sebagaimana tercantum pada Tabel 2.

Tabel 2 
Ringkasan Analisa Regresi terhadap variabel-variabel yang memprediksi Perilaku Kerja Kontraproduktif Organisasi

\begin{tabular}{llll}
\hline & $\boldsymbol{B}$ & $\boldsymbol{S E} \boldsymbol{B}$ & $\boldsymbol{\beta}$ \\
\hline Tahap 1 & & & \\
Constan & $-0,234$ & 0,251 & $-0,064$ \\
Sensitivitas Atasan & $-0,042$ & 0,056 & $0,362 * * *$ \\
Neuroticism & 0,284 & 0,067 & \\
& & & \\
Tahap 2 & & & \\
Constan & $-0,189$ & 0,775 & $-0,092$ \\
Sensitivitas Atasan & $-0,061$ & 0,308 & $0,343^{* *}$ \\
Neuroticism & 0,269 & 0,255 & 0,033 \\
Sensitivititas Atasan $x$ Neuroticism & 0,006 & 0,102 & \\
\hline Note $\mathrm{R}^{2}=0,139$ pada langkah $1 ; \Delta \mathrm{R}^{2}=0,000$ pada langkah $2(p=0,952) . *{ }^{*}<0,05 ; * * p<0,01 ; * * * p<0,001$ & & \\
\hline Efek $m$.
\end{tabular}

Efek moderasi diuji menggunakan prosedur MRA (moderation regression analysis). Prosedur ini menguji dua tahap, tahap pertama adalah pengaruh sensitivitas atasan dan neuroticism pada perilaku kerja kontraproduktiforganisasi, sementara pada tahap kedua interaksi antara sensitivitas atasan dan neuroticism dan neuroticism diikutsertakan kedalam analisis.

Pada tahap pertama ditemukan bahwa secara simultan (bersama-sama) sensitivitas atasan dan neuroticism terbukti mampu memprediksi perilaku kerja kontraproduktif-organisasi $\left(\mathrm{R}^{2}=0,139 ; \mathrm{F}=9.651 ; p=0,000\right)$, namun jika diperhatikan secara parsial diketahui bahwa hanya neuroticism yang signifikan terbukti mampu menjadi prediktor perilaku kerja kontraproduktif-organisasi $(\beta=0,362 ; p=<0,001)$, sementara sensitivitas atasan tidak mampu menjadi prediktor $(\beta=-0,064 ; p=>0,05)$.

Pada tahap kedua diketahui bahwa interaksi antara sensitivitas atasan dan neuroticism tidak signifikan memprediksi perilaku kerja kontraproduktif-organisasi $(\beta=0,033 ; p=>0,05)$, lebih lanjut perubahan $\left(\mathrm{R}^{2}\right)$ antara model pertama dengan model kedua juga ditemukan tidak signifikan $\left(\Delta \mathrm{R}^{2}=0,000 ; \Delta p=>0,05\right)$. Kedua temuan terakhir ini membuktikan bahwa neuroticism tidak terbukti mampu memoderasi relasi antara sensitivitas atasan dengan perilaku kerja kontraproduktif-organisasi.

\section{DISKUSI DAN KESIMPULAN}

Dalam penelitian ini neuroticism tidak berperan sebagai moderator pada hubungan antara sensitivitas atasan dengan perilaku kerja kontraproduktif-organisasi. Tetapi berdasarkan hasil uji MRA, pada tahap 1 dan tahap 2 ditemukan adanya perbedaan signifikansi pada neuroticism. Selain itu juga ditemukan adanya perbedaan besarnya pengaruh variabel-variabel terhadap perilaku kerja kontraroduktif $\left(\mathrm{R}^{2}\right)$ pada tahap 1 dan tahap 2 , menunjukkan neuroticism memiliki potensi untuk berperan menjadi moderator. Tidak terbuktinya neuroticism sebagai moderator diprediksi karena jumlah partisipan yang kurang besar, serta jawaban responden yang tidak 
PENGUJIAN NEUROTICISM SEBAGAI

MODERATOR PADA HUBUNGAN ANTARA

SENSITIVITAS ATASAN DENGAN PERILAKU

KERJA KONTRAPRODUKTIF BAWAHAN

(STUDI KASUS DI PT XYZ)

sesuai dengan perilaku kerja di lapangan. Hal yang sama juga ditemui Pecker dan Fine (2015), yaitu tingkat perilaku kerja kontraproduktif yang cenderung sangat rendah, dan diduga karyawan tidak ingin terdeteksi melakukan perilaku kerja kontraproduktif (Sackett \& DeVore, 2005). Hal ini dapat dikembangkan di penelitian selanjutnya di mana sensivitas atasan dapat dijadikan dependent variable atau moderator.

Diharapkan pada penelitian selanjutnya dapat dilakukan pada seluruh perusahaan asuransi secara nasional sehingga jumlah sampel menjadi lebih besar dan dapat menambah varian. Disarankan pula pada penelitian berikutnya terdapat penilaian atasan terhadap perilaku kerja kontraproduktif bawahan. Saran lain untuk penelitian selanjutnya adalah karena efek moderasi sangat kecil hasilnya, disarankan dilakukan pengujian dengan teknik berbeda, seperti teknik PROCESS pada SPSS.

\section{Ucapan Terima Kasih}

Penulis mengucapkan terima kasih kepada semua pihak yang terlibat dalam penelitian ini, khususnya para partisipan, pihak manajemen perusahaan, serta berbagai pihak yang tidak dapat disebutkan satu persatu

\section{REFERENSI}

Bennett, R. J., \& Robinson, S. L. (2000). Development of a measure of workplace deviance. Journal of Applied Psychology, 85(3), 349-360. doi: 10.I037//0021-9010.85.3.349

Cattell, R., Eysenck, H., \& other trait (2005). The trait approach: The genetics of personality. In Schultz, D. P. \& Schultz, S. E. Theories of personality (eight edition) (pp.249-304). Belmont, CA, USA: Thomson Wadsworth.

ChenLim, L., Yin-Fah, C., Benjamin, \& Jin Teh, C. (2016). The influence of personality traits on volunteers' workplace deviance. The European Proceedings of Social and Behavioural Science (EpSBS) eISSN: 2357-1330. http://dx.doi.org/10.15405/epsbs.2016.08.06

Chullen, C. L., Dunford, B. B., Angermeier, I., Boss, R. W., \& Boss, A. D. (2010). Minimizing deviant behavior in healthcare organizations: The effects of supportive leadership and job design. Journal of Healthcare Management, 55(6), 381-397. ISSN: 1096-9012

Costa, P. T., \& McCrae, R. R. (1992). Revised NEO Personality Inventory (NEO-PI-R) and NEO Five-Factor Inventory (NEO-FFI) professional manual. Odessa, FL: Psychological Assessment Resources 
Demerouti, E., Bakker, A. B., Halbesleben, J. R. B. (2015). Productive and counterproductive job crafting: A daily diary study. Journal of Occupational Health, 20(4), pp.457-469. http://dx.doi.org/10.1037/a0039002

Dunlop, P. D., \& Lee, K. (2004). Workplace deviance, organizational citizenship behavior, and business unit performance: The bad apples do spoil the whole barrel. Journal of Organizational Behavior, 25(1), 67-80. doi: 10.1002/job.243

Epitropaki, O., \& Martin, R. (2005). From ideal to real: A longitudinal study of the role of implicit leadership theories on leader-member exchanges and employee outcomes. Journal of Applied Psychology, 90(4), 659-676. doi: 10.1037/0021-9010.90.4.659

Fida, R., Paciello, M., Tramontano, C., Fontaine, R. G., Barbaranelli, C., \& Farnese, M. L. (2016). An integrative approach to understanding counterproductive work behavior: The roles of stressors, negative emotions, and moral disengagement. Journal of Business Ethics, 130(1), 131144. ISSN Print: 0167-4544, Online: 1573-0697, doi: 10.1007/s10551-014-2209-5

Golparvar, M., Dehghan, S., \& Mehdad, A. (2014). Relationship between emotional exhaustion and deviant behaviors: Moderating role of big five personality traits. International Journal of Scientific Research in Knowledge, 2(6), 285-296. ISSN: 2322-4541. http://dx.doi.org/10.12983/ijsrk-2014-p0285-0296

Judge, T. A., Locke, E. A., Durham, C. C., \& Kluger, A. N. (1998). Dispositional effects on job and life satisfaction: The role of core evaluations. Journal of Applied Psychology, 83(1), 17-34

Kozako, I. N. A. M. F., Safin, S. Z., \& Rahim, A. R. A. (2013). The relationship of big five personality traits on counterproductive work behaviour among hotel employees: An exploratory study. International Conference on Economics and Business Research (ICEBR), Procedia Economics and Finance 7, $181-187$.

McCrae, R. R. \& Costa, P. T. Jr. (1987). Validation of the five-factor model of personality across instruments and observers. Journal of Personality and Social Psychology, 52(1), 81-90.

Mount, M., Ilies, R., Johnson, E. (2006). Relationship of personality traits and counterproductive work behaviors: The mediating effects of job satisfaction. Personnel Psychology, 59, 591-622.

Offermann, L. R., Kennedy Jr., J. K., \& Wirtz, P. W. (1994). Implicit leadership theories: Content, structure, and generalizability. Leadership Quarterly, S(1), 43-58. JAI Press Inc. ISSN: 10489843

Ozbag, G. K. (2016). The role of personality in leadership: Five factor personality traits and ethical leadership. Procedia - Social and Behavioral Sciences, 235, 235-242, doi: 10.1016/j.sbspro.2016.11.019

Pecker, G. \& Fine, S. (2015). Using exit surveys to assess counterproductive work behaviors: A case study. Psychological Reports: Employment Psychology \& Marketing, 116(1), 89-96. doi: 10.2466/01.PR0.116k16w4. ISSN: 0033-2941

Robinson, S. L., \& Bennett, R. J. (1995). A typology of deviant workplace behaviors: A multidimensional scaling study. Academy of Management Jurnal, 38(2), 555-572.

Rupprecht, E. A., Kueny, C. R., Shoss, M. K., \& Metzger, A. J. (2016). Getting what you want: How fit between desired and received leader sensitivity influences emotion and counterproductive 
PENGUJIAN NEUROTICISM SEBAGAI

Tri Hartati, Rostiana dan P. Tommy Y.S Suyasa

MODERATOR PADA HUBUNGAN ANTARA

SENSITIVITAS ATASAN DENGAN PERILAKU

KERJA KONTRAPRODUKTIF BAWAHAN

(STUDI KASUS DI PT XYZ)

work behavior. Journal of Occupational Health Psychology, 21(4), 443-454. http://dx.doi.org/10.1037/a0040074

Sackett, P. R., \& DeVore, C. J. (2005). Counterproductive behaviors at work. In Anderson, N.,

Ones, D. S., Sinangil, H. K., Viswesvaran, C (Eds.), Handbook of industrial, work and

organizational psychology (Volume 1 Personnel psychology) (pp. 145-164). Great Britain, London:

Sage Publications.

Schultz, D. P. \& Schultz, S. E. (2005). Theories of personality (eight edition). Belmont, CA, USA: Thomson Wadsworth.

Spector, P. E., Fox, S., Penney, L. M., Bruursema, K., Goh, A., \& Kessler, S. (2006). The dimensionality of counterproductivity: Are all counterproductive behaviors created equal? Journal of Vocational Behavior 68, 446-460. doi:10.1016/j.jvb.2005.10.005

Sulea, C., Fine, S., Fischmann, G., Sava, F. A., \& Dumitru, C. (2013). Abusive supervision and counterproductive work behaviors: The moderating effects of personality. Journal of Personnel Psychology, 12(4), 196-200, doi:10.1027/1866-5888/a000097.

Teferi, T. B. (2004). The application of the NEO-PI-R in the Eritrean context. A dissertation submitted to the Faculty of Humanities, University of the Witwatersrand, Johannesburg, in fulfillment of the requirements for the Degree of Master of Arts (Psychology). 